\title{
A Fuzzy AHP Approach to Select Learning Management System
}

\author{
Ali Hakan Işık, Murat İnce, and Tuncay Yiğit
}

\begin{abstract}
A great deal of learning management system (LMS) are available in e-learning environment. Each LMS has distinguished technical and educational features. Due to the diversity of these systems and increase in demand, choosing the most appropriate one that meets our priorities becomes challenging issue. In addition, determination of suitable LMS can be accepted as a multi-criteria decision making (MCDM) problem. In this context, Fuzzy Analytic Hierarchy Process (FAHP) which is a popular MCDM method is used for selection of the appropriate LMS. It provides objective expert evaluation. Obtained results show that Joomla LMS is the best LMS that meets our criteria.
\end{abstract}

Index Terms-Fuzzy AHP, learning management system, multi-criteria decision making, triangular fuzzy numbers.

\section{INTRODUCTION}

Developments in web technologies cause different and excessive usage of computer systems in education. Various organizations such as institutions, schools, universities and even commercial companies use computers for educational purposes. Using of computers systems in education can be enabled by LMSs. Due to the increase in the variety and quantity of LMSs, the problem of the selecting the most suitable and best LMS is arisen.

For instance, there are huge amount of LMS which have a lot of technical and pedagogical properties. Therefore, how can they be selected correctly according to the needs and priorities of the learners and also organizations? How it can be decided? These questions can be answered by the help of the MCDM methods. In this paper, a fuzzy analytic hierarchy process is used for the selection of the learning management system.

This study is organized in four sections. In the first section, the matter of LMS selection with Fuzzy AHP is introduced. In the second section, method of our study is given. In the third section, results about the system are presented. Finally, the conclusion and future works related to the Fuzzy AHP approach to select learning management system issue are given.

Manuscript received August 17, 2014; revised October 16, 2014

Ali Hakan Iș1k is with the Department of Computer Engineering, University of Mehmet AkifErsoy, Burdur 15030, Turkey (e-mail: ahakan@mehmetakif.edu.tr).

Murat İnce is with Computer Technology, Vocational School of Technical Sciences, University of Suleyman Demirel, Isparta 32200, Turkey (e-mail: muratince@sdu.edu.tr).

Tuncay Yiğit is with the Department of Computer Engineering, University of Suleyman Demirel, Isparta 32200, Turkey (e-mail: tuncayyigit@sdu.edu.tr).

\section{LMS SELECTION WITH FUZZY AHP}

Selection of the best LMS according to the priorities of needs can be provided by MDCM methods. For this evaluation process, criteria are defined and applied to choose bestLMS among alternatives by using comparison sets. A quantitative approach with spreadsheet might have been a solution to this problem [1]. However, finding the most effective and easy MCDM method is not easy for LMS selection issue. It requires time for the implementation of MCDM methods, evaluation of criteria and alternatives [2].

\section{METHOD}

Analytical hierarchy process (AHP) method was developed by Saaty [3]. This method is successfully applied to different types of MCDM problems [4]. Although its popularity, AHP is criticized for its inability to handle uncertain and imprecise decision maker's evaluations [5]. In AHP, human's judgments are presented as crisp (exact) numbers but in many cases human preferences are uncertain to assign exact numbers to comparisons of the alternatives and criteria [6]. In order to cope with uncertain judgments comparisons of alternatives and criteria can be expressed as fuzzy sets or fuzzy numbers which incorporate the vagueness of the human preferences [6]. These fuzzy set can be provided by the most popular MCDM method which is Fuzzy Analytical Hierarchy Process [7]-[10]. FAHP is implemented in different fields as follows:

1) Supplier selection [11]

2) Selection computer integrated manufacturing systems [12]

3) Consideration of global supplier development risk factors [13]

4) Selection of the best catering service firm [7]

5) Evaluation of success factors for e-commerce [14]

6) Selection of convenience store location [15]

7) Job evaluation [16]

8) Evaluation of IT department performance [17]

9) Evaluation of the architectural design services [18]

10) Evaluation of services [6]

11) Selection of optimum underground mining method [19]

12) Selection of ERP software [20]

13) Selection of academic staff [21]

14) Analysis of fuel management [22]

15) Assessment of water management plans [23]

Generally, imprecise judgments are used rather than precise judgments in daily life. In FAHP, crisp values of the decision makers are expressed as fuzzy comparison sets (fuzzy triangular numbers). It uses derivative fuzzy ratios instead of crisp priorities in AHP because decision maker 
preferences in AHP are based on perception but the FAHP is more representative for decisions of humans[24]. Due to these reasons, FAHP is used as a MCDM method in our study.

The decision hierarchy of the criteria and the alternatives of our study are same as the Çetin's and his colleagues work [2], as shown in Fig. 1. Atutor, Black Board, Dokeos, E-nocta, HotChalk, Ilias, JoomLA, Moodle, Sakai Project, Sumtotal systems are the candidate alternatives for selection process of the best LMS. In our study, defined criteria are compared with each other representatively by Triangular Fuzzy Numbers(TFN) in a matrix. TFN are given in Table I [25]. TFN pair-wise comparison matrix of criteria is given in Table II.

\begin{tabular}{lll}
\multicolumn{2}{c}{ TABLE I: TFN PAIR-WISE COMPARISON MATRIX OF CRITERIA } \\
\hline \hline Linguistic Variables & TFNs & Reciprocal of TFNs 2 \\
\hline Equally Preferred & $1,1,1$ & $1,1,1$ \\
Moderately Preferred & $0.66,1,1.5$ & $0.66,1,1.5$ \\
Strongly Preferred & $1.5,2,2.5$ & $0.4,0.5,0.66$ \\
Very Strongly Preferred & $2.5,3,3.5$ & $0.285,0.333,0.4$ \\
Extremely Preferred & $3.5,4,4.5$ & $0.222,0.25,0.285$ \\
\hline \hline
\end{tabular}

The steps of the FAHP are given as follows. It also includes TFNs [11]:

Step 1: The value of fuzzy synthetic extent with respect to the $i^{\text {th }}$ object is defined as:

$$
S_{i}=\sum_{j=i}^{m} M_{g i}^{j} \otimes\left[\sum_{i=1}^{n} \sum_{j=1}^{m} M_{g i}^{j}\right]^{-1}
$$

To obtain $\sum_{j=i}^{m} M_{g i}^{j}$, and perform the fuzzy addition operation of $m$ extent analysis values for a particular matrix such that:

$$
\sum_{j=i}^{m} M_{g i}^{j}=\left(\sum_{j=1}^{m} l_{j}, \sum_{j=1}^{m} m_{j}, \sum_{j=1}^{m} u_{j}\right)
$$

and to obtain $\left[\sum_{i=1}^{n} \sum_{j=1}^{m} M_{g i}^{j}\right]^{-1}$, and perform the fuzzy addition operation of $M_{g i}^{j}(j=1,2, \ldots, m)$ values such that

$$
\sum_{i=1}^{n} \sum_{j=1}^{m} M_{g i}^{j}=\sum_{i=1}^{n} l_{i}, \sum_{i=1}^{n} m_{i}, \sum_{i=1}^{n} u_{i}
$$

and then compute the inverse of the vector above, such that:

$$
\left[\sum_{i=1}^{n} \sum_{j=1}^{m} M_{g i}^{j}\right]^{-1}=\left(\frac{1}{\sum_{i=1}^{n} u_{i}}, \frac{1}{\sum_{i=1}^{n} m_{i}}, \frac{1}{\sum_{i=1}^{n} l_{i}}\right)
$$

Step 2: As $M_{1}^{\sim}=\left(l_{1} m_{1} u_{1}\right)$ and $M_{2}^{\sim}=\left(l_{2} m_{2} u_{2}\right)$ are two TFNs, the degree of possibility of $M_{2}=\left(l_{2} m_{2} u_{2}\right) \geq M_{1}=$ $\left(l_{1} m_{1} u_{1}\right)$ defined as:

$$
V\left(M_{2}^{\sim} \geq M_{1}^{\sim}\right)=\sup _{y \geq x}\left\lfloor\min \left(\mu_{M_{1}^{\tau}}(x), \mu_{M_{2}^{\sim}}(y)\right)\right\rfloor
$$

and can be equivalently expressed as follows:

$$
\begin{aligned}
& V\left(M_{2}^{\sim} \geq M_{1}^{\sim}\right)=\operatorname{hgt}\left(M_{1}^{\sim} \cap M_{2}^{\sim}\right)=\mu_{M_{2}}(d) \\
& 1, \text { if } m_{2} \geq m_{1} \\
& 0, \text { if } l_{1} \geq u_{2} \\
& \text { otherwise, } \frac{l_{1}-u_{2}}{\left(m_{2}-u_{2}\right)-\left(m_{1}-l_{1}\right)}
\end{aligned}
$$

Step 3: The degree possibility for a convex fuzzy number to be greater than k convex fuzzy $M_{i}(1,2, k)$ numbers can be defined by

$$
\begin{aligned}
& V\left(M \geq M_{1}, M_{2}, \ldots . M_{k}\right)=V\left[\left(M \geq M_{1}\right)\right. \\
& \text { and } \left.\left(M \geq M_{2}\right) \text { and } \ldots . \text { and }\left(M \geq M_{k}\right)\right] \\
& =\min V\left(M \geq M_{i}\right), i=1,2,3, \ldots ., k
\end{aligned}
$$

Assume that $d\left(A_{i}\right)=\operatorname{minV}\left(S_{i} \geq S_{k}\right)$ for $k=$ $1,2, \ldots \ldots, n ; k \neq i$. Then the weight vector is given by

$$
W^{\prime}=\left(d^{\prime}\left(A_{1}\right), d^{\prime}\left(A_{2}\right), \ldots d^{\prime}\left(A_{n}\right)\right)^{T}
$$

where $A_{i}=(i=1,2, \ldots, n)$ are $n$ elements.

\begin{tabular}{|c|c|c|c|c|c|c|c|c|c|}
\hline & Multilanguage & Cost & Evaluative Tools & Compatibility & Support & Sustainability & Reliability & Source Code & Management \\
\hline Multilanguage & $1,1,1$ & $\begin{array}{l}0.66 \\
1,1.5\end{array}$ & $0.66,1,1.5$ & $0.66,1,1.5$ & $0.66,1,1.5$ & $0.66,1,1.5$ & $\begin{array}{l}0.40,0.50 \text {, } \\
0.66\end{array}$ & $0.66,1,1.5$ & $\begin{array}{l}0.285,0.250 \text {, } \\
0.285\end{array}$ \\
\hline Cost & & $1,1,1$ & $\begin{array}{l}0.285,0.250 \\
0.285\end{array}$ & $0.66,1,1.5$ & $0.66,1,1.5$ & $1,1,1$ & $\begin{array}{l}0.222,0.250 \\
0.285\end{array}$ & $1,1,1$ & $\begin{array}{l}0.285,0.250 \\
0.285\end{array}$ \\
\hline Evaluative & & & & & & & $0.285,0.250$, & & \\
\hline Tools & & & $1,1,1$ & $0.66,1,1.5$ & $0.66,1,1.5$ & $0.66,1,1.5$ & $\begin{array}{l}0.285 \\
0.285,0.250\end{array}$ & $1.5,2,2.5$ & $\begin{array}{l}0.66,1,1.5 \\
0.40,0.50\end{array}$ \\
\hline Compatibility & & & & $1,1,1$ & $0.66,1,1.5$ & $0.66,1,1.5$ & 0.285 & $0.66,1,1.5$ & 0.66 \\
\hline Support & & & & & $1,1,1$ & $1,1,1$ & $\begin{array}{l}0.285,0.250 \\
0.285\end{array}$ & $0.66,1,1.5$ & $\begin{array}{l}0.285,0.250, \\
0.285\end{array}$ \\
\hline Sustainability & & & & & & $1,1,1$ & $\begin{array}{l}0.285,0.250 \\
0.285\end{array}$ & $1,1,1$ & $\begin{array}{l}0.285,0.250 \\
0.285\end{array}$ \\
\hline Reliability & & & & & & & $1,1,1$ & $2.5,3,3.5$ & $0.66,1,1.5$ \\
\hline
\end{tabular}

Step 4: By normalization, the normalized weight vectors are

$$
W=\left(d\left(A_{1}\right), d\left(A_{2}\right), \ldots d\left(A_{n}\right)\right)^{T}
$$

where $W$ is a non-fuzzy number.

Step 5: Check the consistency of matrices to ensure that the judgments of decision makers are consistent.

Step 6: Aggregate the relative weights of decision elements to obtain an overall rating for the alternatives.

TABLE II: TFN PAIR-WISE COMPARISON MATRIX OF CRITERIA 


\begin{tabular}{|c|c|c|}
\hline Source Code & $1,1,1$ & $\begin{array}{l}0.285,0.250 \\
0.285\end{array}$ \\
\hline Management & & $1,1,1$ \\
\hline
\end{tabular}

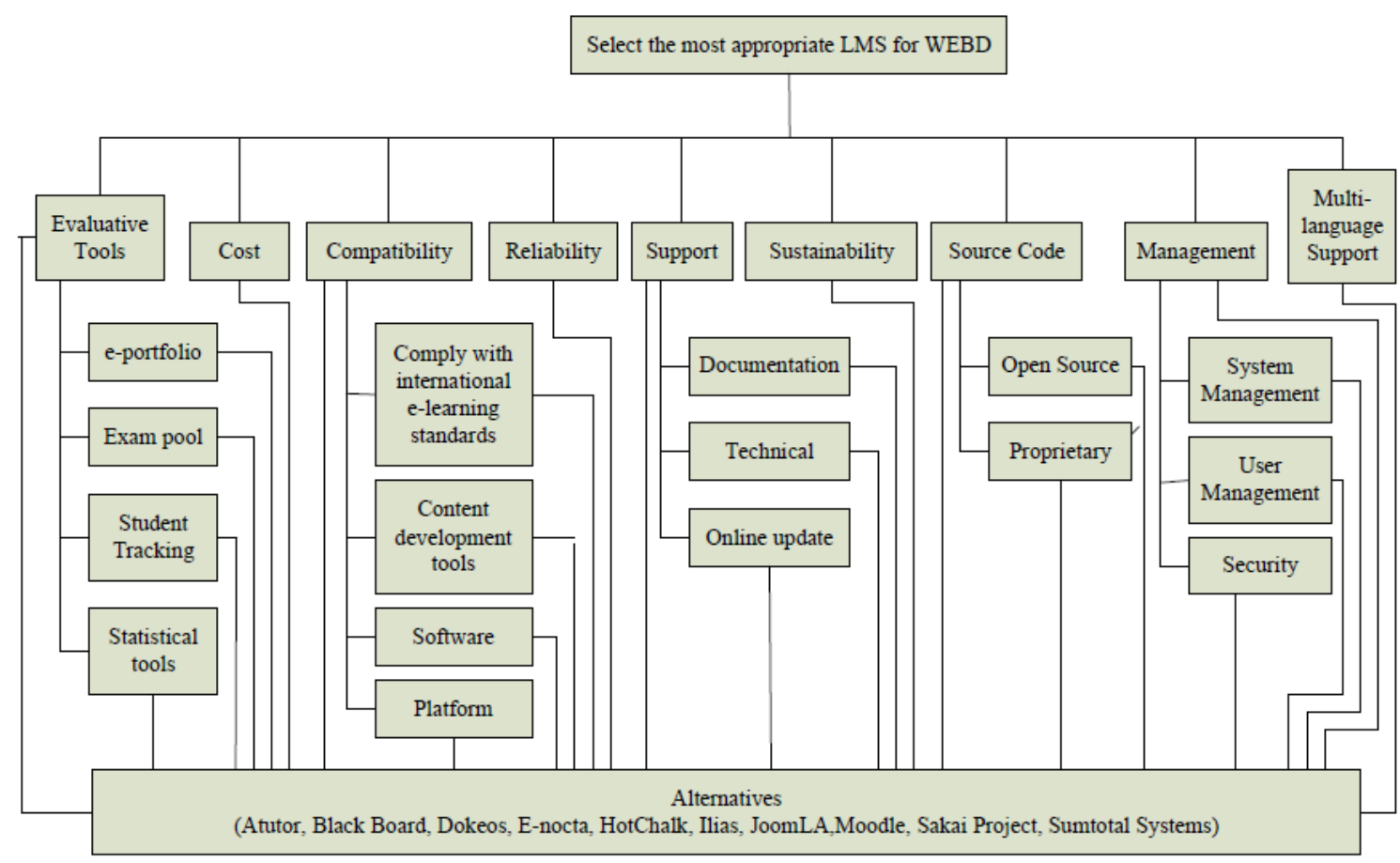

Fig. 1. Decision hierarchy model of the LMS [2].

\section{RESULTS}

While applying this comparison matrix, Consistency Ratio(CR) of the criteria is controlled. If the results are greater than 0.1 , pair-wise comparisons are continue up to $\mathrm{CR}$ value is smaller than 0.1 . In this study, three defuzzification methods are used to calculate CR values, as shown in Table III. We found all CR value smaller than 0.1 with three defuzzification methods. Thus, we can say that defined criteria are consistent.

\begin{tabular}{ll}
\multicolumn{2}{c}{ TABLE III: CR VALUES OF DEFUZZIFICATION METHODS } \\
\hline \hline Defuzzification Method & Consistency Ratio(CR) \\
\hline Centroid & 0.095641 \\
Weighted & 0.085859 \\
Bisector & 0.076077 \\
\hline \hline
\end{tabular}

Weights of the criteria are shown in Table IV. Percentages of the criteria weights based on the TFN representative comparisons can be seen in Fig. 2. Most important criteria are respectively Evaluative Tools, Reliability and Sustainability.

\begin{tabular}{ll}
\multicolumn{2}{c}{ TABLE IV: WEIGHTS OF THE CRITERIA } \\
\hline \hline Criteria & Weights \\
\hline Multilanguage & 0.078191 \\
Cost & 0.079297 \\
Evaluative Tools & 0.182865 \\
Compatibility & 0.082892 \\
Support & 0.076385 \\
Sustainability & 0.134108 \\
Reliability & 0.149208 \\
Source Code & 0.112581 \\
Management & 0.104468 \\
\hline \hline
\end{tabular}

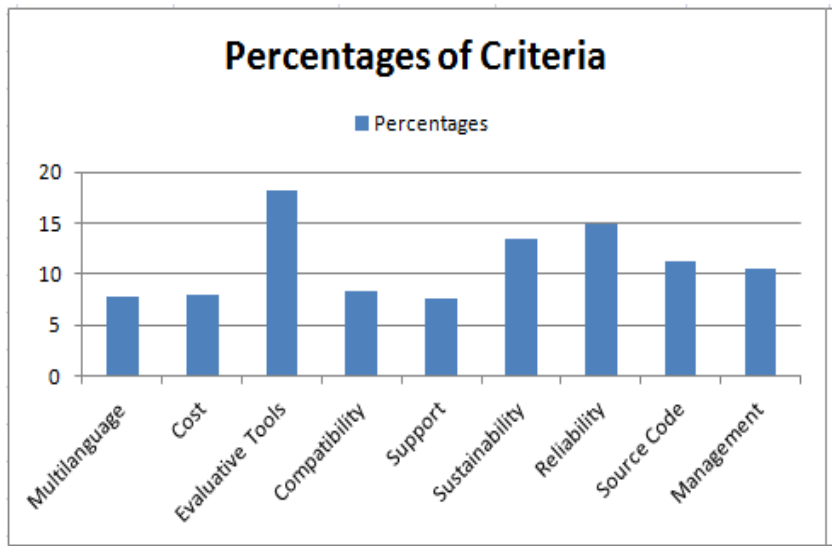

Fig. 2. Weight percentages of TFN scale based judgments of criteria.

\begin{tabular}{ll}
\multicolumn{2}{l}{ TABLE V: OVERALL SCORE OF THE ALTERNATIVE LMSS } \\
\hline \hline LMS & Percentage of Score (\%) \\
\hline Joomla LMS & 11.64015 \\
SumTotal Systems & 11.52187 \\
Moodle & 10.98746 \\
Dokeos & 10.94606 \\
ILIAS & 10.87451 \\
Enocta & 10.31658 \\
Sakai Project & 9.845055 \\
Hotchalk & 9.699771 \\
Blackboard & 7.307526 \\
Atutor & 6.860209 \\
\hline \hline
\end{tabular}

According to the defined criteria, the overall scores of the alternative LMSs are shown in Table V. Results show that Joomla LMS is the best learning management system regarding our priorities. If priorities and preferences are altered, results of this selection MCDM problem can also be changed. Therefore, saying that the Joomla is the best LMS 
among other LMSs might be misleading. It would be better to say that according to the given priorities Joomla is the best LMS for our study.

\section{CONCLUSION}

FAHP is a popular MCDM method. In our study, it is used for the selection of the most appropriate LMS according to our priorities and preferences. Using of FAHP in this type of selection problem, it provide reliable resultsdue to the fact that imprecise and uncertain preferences of the users can be expressed as fuzzy sets (TFNs). In addition, three different defuzzification methods are utilized for the calculation of the CR of pair-wise criteria comparisons. According to our priorities, Joomla LMS is the most appropriate LMS that meets our criteria. Developed software that use FAHP method has a modular infrastructure. Thus, it can be used for different types of MCDM problems.

\section{REFERENCES}

[1] M. S. Bandor, "Quantitative methods for software selection and evaluation," Camegie Melon University, Technical Note, September 2006.

[2] A. Çetin, A. H. Işık, and I. Güler, "Learning management system selection with analytic hierarchy process," in Proc. 13th Int. Conf. on Interactive Computer Aided Learning, Hasselt, Belgium, 2010, pp. 921-926.

[3] T. L. Saaty, The Analytic Hierarchy Process, New York: McGraw Hill, 1980.

[4] T. L. Saaty, Multicriteria Decision Making: the Analytic Hierarchy Process, Pittsburgh PA: RWS Publications, 1988.

[5] H. Deng, "Multicriteria analysis with fuzzy pairwise comparisons," Int. J. Approximate Reasoning, vol. 21, pp. 215-231, 1999.

[6] L. Mikhailov and P. Tsvetinov, "Evaluation of services using a fuzzy analytic hierarchy process," Applied Soft Computing, vol. 5, no. 1, pp. 23-33, 2004.

[7] C. Kahraman, U. Cebeci, and D. Ruan, "Multi-attribute comparison of catering service companies using fuzzy AHP: The case of Turkey," International of Production Economics, vol. 87, pp. 171-184, 2004.

[8] F, Ghotb and L. Warren, "A case study comparison of the analytic hierarchy process and a fuzzy decision methodology," The Engineering Economist, vol. 40, pp. 233-247, 1995.

[9] R. Zhau and R. Goving, "Algebraic characteristics of extended fuzzy numbers," Information Science, vol. 54, pp. 103-130, 1991.

[10] J. Y. Teng and G. H. Tzeng, "Fuzzy multicriteria ranking of urban transportation investment alternative," Transportation Planning and Technology, vol. 20, pp. 15-31, 1996.

[11] A. Aktepe and S. Ersöz, "A fuzzy analytic hierarchy process model for supplier selection and a case study," International Journal of Research and Development, vol. 3, no. 1, pp. 33-37, 2011.

[12] C. E. Bozdağ, C. Kahraman, and D. Ruan, "Fuzzy group decision making for selection among computer integrated manufacturing systems," Comput. Ind., vol. 5, pp. 13-29, 2003.

[13] F. T. S. Chan and N. Kumar, "Global supplier development considering risk factors using fuzzy extended AHPbased approach," Omega. Oxf., vol. 35, pp. 417-431, 2007.

[14] F. Kong and H. Liu, "Applying fuzzy analytic hierarchy process to evaluate success factors of E-commerce," International Journal of Information and Systems Sciences, vol. 1, pp. 406-412, 2005.

[15] R. J. Kuo, S. C. Chi, and S. S. Kao, "A decision support system for selecting convenience store location through integration of fuzzy AHP and artificial neural network," Comput. Ind., vol. 47, pp. 199-214, 2002.
[16] A. C. Kutlu, M. Ekmekçioğlu, and C. Kahraman, "A fuzzy multi-criteria approach to point-factor method for job evaluation," Journal of Intelligent and Fuzzy Systems, vol. 25, pp. 659-671, 2013.

[17] A. H. Lee, W. C. Chen, and C. J. Chang, "A fuzzy AHP and BSC approach for evaluating performance of IT department in the manufacturing industry in Taiwan," Expert Systems with Applications, vol. 34, pp. 96-107, 2008.

[18] J. Li and S. Chen, "Evaluating the architectural design services by using Fuzzy AHP," Bus. Rev. Cambr., vol. 1, pp. 129-137, 2009.

[19] M. Z. Naghadehi, R. Mikaeil, and M. Ataei, "The application of fuzzy analytic hierarchy process (FAHP) approach to selection of optimum underground mining method for Jajarm Bauxite Mine," Expert Systems with Applications, vol. 36, pp. 8218-8226, 2009.

[20] S. Onut and T. Efendigil, "A theorical model design for ERP software selection process under the constraints of cost and quality: A fuzzy approach," Journal of Intelligent and Fuzzy Systems, vol. 21, pp. 365-378, 2010.

[21] B. D. Rouyendegh and T. E. Erkan, "Selection of academic staff using the fuzzy analytic hierarchy process (FAHP): A pilot study," Tehni?kivjesnik, vol. 19, pp. 923-929, 2012.

[22] K. Y. Sohn, J. W. Yang, and C. S. Kang, "Assimilation of public opinions in nuclear decision-making using risk perception," Ann. Nucl. Energ., vol. 28, pp. 553-563, 2001.

[23] B. Srdjevic and Y. D. P. Medeiros, "Fuzzy AHP assessment of water management plans," Water Resour. Manag., vol. 22, pp. 877-894, 2008.

[24] A. C. Cheng, C. J. Chen, and C. Y. Chen, " A fuzzy multiple criteria comparison of technology forecasting methods for predicting the new materials development," Technological Forecasting and Social Change, vol. 75, no. 1, pp. 131-141, 2008.

[25] D. Y. Chang, "Applications of the extent analysis method on fuzzy AHP," European Journal of Operational Research, vol. 95, no. 3, pp 649-655, 1996.

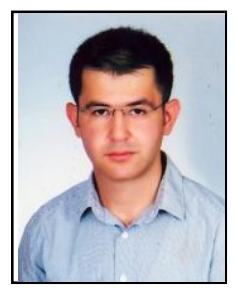

Ali Hakan Ișik received the B.S. degree in 2002 from Electrical and Electronics Engineering of Gazi University, Turkey. He received the M.S. degree in 2005 from Gazi University, Turkey and completed Ph.D. degree in 2012 at Gazi University. He is currently an assistant professor at the Department of Computer Engineering in Mehmet Akif Ersoy University. His reasearch interest includes engineering education, biomedical and distance education.

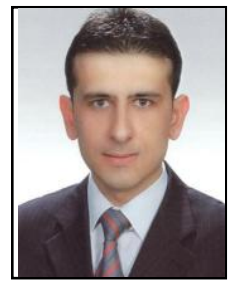

Murat Ince received the B.S. degree in 2009 from Education Faculty of Middle East Technical University, Turkey. He received the M.S. degree in 2012 from Suleyman Demirel University in 2012. He is currently a research assistant at the Vocational School of Technical Sciences in Suleyman Demirel university. His research interest includes expert systems, software development and distance education.

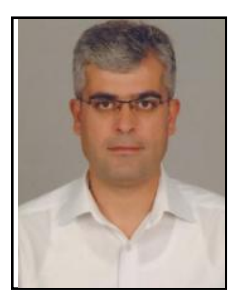

Tuncay Yiğit received the B.S. degree in 1997 from the Technical Education Faculty of Gazi University, Turkey. He received the M.S. degree in 2000 from Gazi University, Turkey and completed the $\mathrm{Ph}$. D. degree in 2005 at Gazi University. He is currently an associative professor at the Department of Computer Engineering in Suleyman Demirel university. His research interest includes software technologies, information systems. 